\title{
STUDY OF THE RELATIONSHIP BETWEEN GLYCOSYLATED HEMOGLOBIN, HOMA IR AND SERUM GLUCOSE IN ACUTE ISCHEMIC STROKE IN THE DIABETIC PATIENT
}

\author{
Nicolae Ovidiu Pop $p^{1,2}$, Aurel George Mohan ${ }^{1,2}$, Dana Carmen Zaha², Florica Mekereș², \\ Petru Aurel Babeș ${ }^{2}$ \\ ${ }^{1}$ Oradea County Emergency Clinical Hospital, Romania \\ ${ }^{2}$ Faculty of Medicine and Pharmacy, University of Oradea, Oradea, Romania \\ Corresponding author: pop_ovidiu212@yahoo.com
}

\section{Abstract}

Determination of serum glycosylated hemoglobin, blood glucose and insulinemia (Homa IR) can be used in the assessment and prognosis of patients with diabetic versus non-diabetic acute ischemic stroke.

Keywords: glycosylated hemoglobin, Homa IR, glucose, stroke.

\section{Abstract}

Determinarea nivelului seric al hemoglobinei glicozilate, glicemiei și insulinemiei (Homa IR) poate fi folosită în evaluarea și prognosticul pacientului cu accident vascular ischemic acut diabetic versus non diabetic.

Cuvinte cheie: hemoglobină glicozilată, Homa IR, glucoză, stroke.

\section{Introduction}

Diabetes is an independent risk factor for stroke and is associated with increased mortality. The increased risk is associated with the pathophysiological changes observed in the cerebral vessels of diabetic patients ${ }^{(1)}$. Stroke is one of the leading causes of death worldwide, being the second leading cause of death in many countries. The frequency of ischemic stroke is $75 \%{ }^{(2)}$. Some recent studies suggest that glycosylated hemoglobin may have prognostic value in patients with acute ischemic stroke ${ }^{(3)}$.

About $40 \%$ of patients with ischemic stroke have hyperglycemia at admission and most of them have diabetes ${ }^{(4,5)}$. Insulin resistance has been shown to be associated with activation of coagulation and fibrinolysis, which are of importance in the acute ischemic phase ${ }^{(6,7,8,9)}$. Although pathophysiological aspects are still unclear, 


\section{INTERNAL}

\section{Original papers}

his condition is associated with increased mortality and morbidity in patients with acute ischemic stroke ${ }^{(10,11)}$.

\section{Objectives}

The aim of our study is to present the importance of the relationship of glycosylated hemoglobin level, HOMA IR, serum glucose level and survival in acute ischemic stroke in diabetic versus nondiabetic patient.

\section{Material and method}

This study is of a prospective, observational, longitudinal type conducted within the Oradea County Emergency Clinical Hospital between 2016-2019. In the study, 340 female and male patients aged $40-90$ years were enrolled.

Patients were divided into 2 diabetic and nondiabetic groups, where we analyzed as the main criterion the glycosylated hemoglobin serum level, the HOMA IR and the serum glucose level in the diabetic versus nondiabetic patient with acute ischemic stroke. Serum glucose level, glycosylated hemoglobin and HOMA IR was evaluated at admission to our center, and the examination was performed in case of serum glucose, working method spectrophotometry, on Architect ci4100 analyzer, glycosylated hemoglobin was performed from whole blood, method spectrophotometry working on Architect c4000 analyzer, insulinemia was performed from serum, working method chemiluminescence on Architect ci4100 analyzer.

\section{Results}

According to Kaplan Meyer analysis, diabetic patients had a lower survival rate, with a statistically significant difference $p=0.01$, and after approximately 20 days from admission the survival ratio becomes insignificant between diabetic and nondiabetic patients and practically the survival curves are overlap (figure 1 ).

Glycosylated hemoglobin levels were higher in the dead patients group than in the surviving patients group, so a glycosylated hemoglobin value of $7.32(95 \% \mathrm{Cl}$ for the mean 6) was recorded in the dead patients group 6.6867 to 7.9669 ) and in the group of surviving patients an average glycosylated hemoglobin value of $6.54(95 \% \mathrm{Cl}$ for the mean 6.3109 to 6.7700 ), the analysis being statistically significant $p=0.0088$ (figure 2 ).

We observed an association of the increased HOMA IR with a higher probability of death among patients with ischemic stroke, thus registering an arithmetic mean of the group of dead patients of 6.85 with a $(95 \% \mathrm{Cl}$ for the mean 4.9474 to 8.7633 ), and in the group of 


\section{Survival proportions}

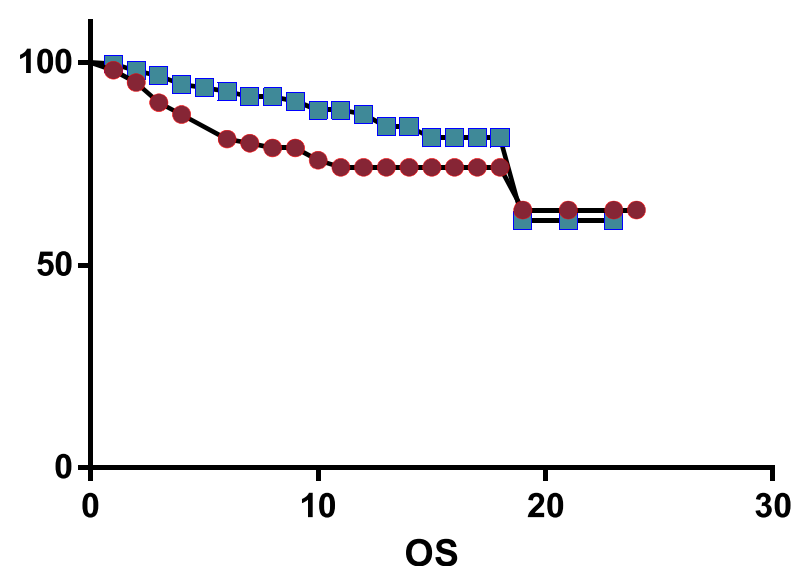

$\rightarrow$ Diabetics

$\rightarrow-$ Non-diabetics

Figure 1. Survival in the diabetic versus non-diabetic patient in the patient with acute ischemic stroke

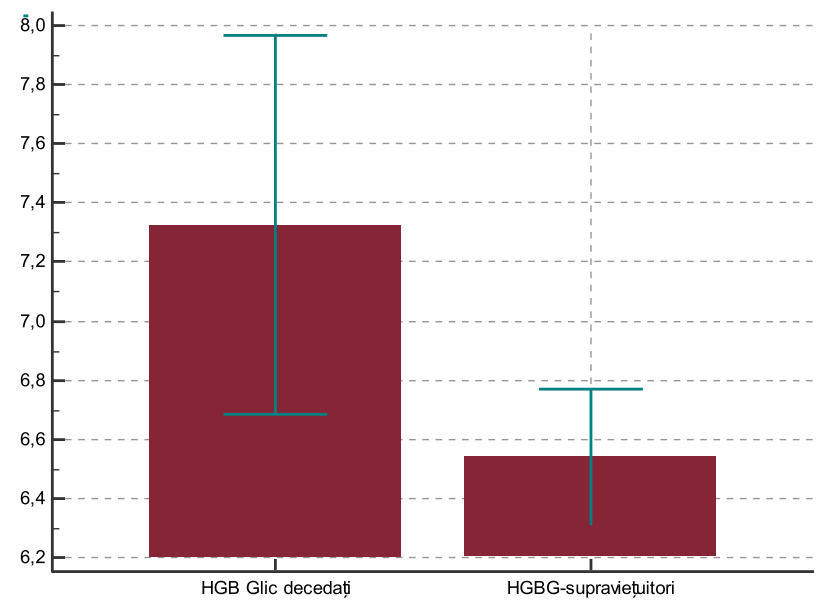

Figure 2. Glycosylated hemoglobin level in patients with acute ischemic stroke. Survivors versus non-survivors

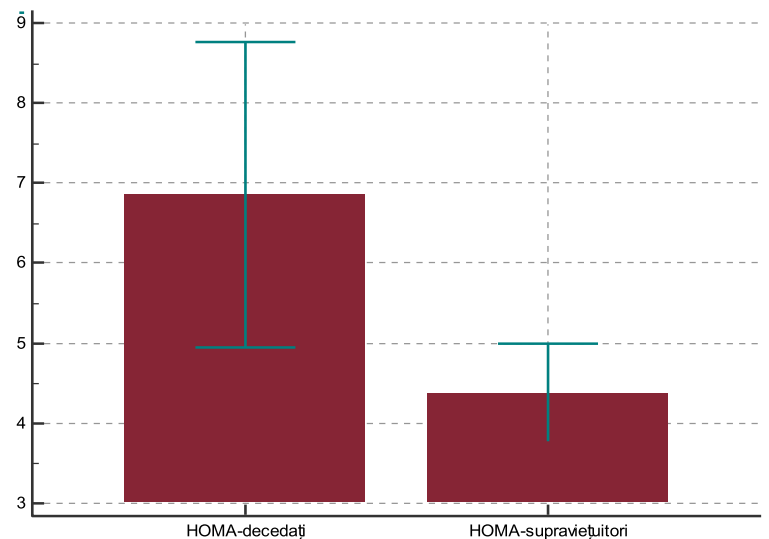

Figure 3. HOMA IR in patients with acute ischemic stroke. Non-survivors vs. survivors 


\section{INTER \\ Original papers}

\section{Unpaired $\mathbf{t}$ test data}

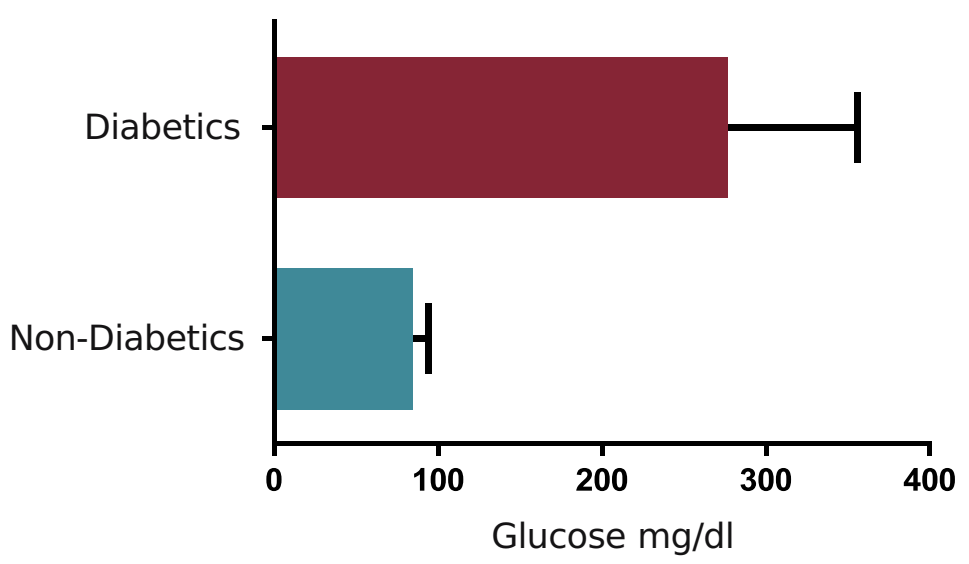

Figure 4. Blood glucose level of diabetic versus non-diabetic patients with acute ischemic stroke at admission

surviving patients an arithmetic mean of 4.38 (95\% Cl for the mean 3.7740 to 4.9929 ). The analysis is statistically significant $p=0.001$ (Figure 3). Medium glucose levels were recorded among patients with non-diabetic acute ischemic stroke with an average value of $84.56 \pm 0.6171$, and among diabetic patients an average value of $276.9 \pm 7.864$ with $(95 \%$ $\mathrm{Cl}$ for the mean 182.1 to 202.5 ) this analysis being highly statistically significant $p<0.0001$ (figure 4).

\section{Discussions}

According to our study, diabetic patients have a lower survival rate than non-diabetic patients in the first 20 days after admission, after which the difference becomes insignificant between the 2 groups. Some studies show an increase in short-term mortality of patients with acute diabetic ischemic stroke compared to nondiabetics ${ }^{(12,13,14,15)}$.

Diabetes increases mortality in acute ischemic stroke independent of other factors such as baseline severity and ischemic heart disease ${ }^{(16)}$. Studies show a relationship between glycosylated hemoglobin level and mortality in the diabetic patient ${ }^{(17,18)}$.

There are studies that show that insulin resistance significantly increases the risk of acute ischemic stroke and leads to poor 
prognosis ${ }^{(19)}$. Hyperglycemia has been shown to be a poor prognostic marker in acute ischemic stroke ${ }^{(20)}$.

\section{Conclusions}

Following the analysis of the relationship between glycosylated hemoglobin, Homa IR and serum glucose level in acute ischemic stroke in the diabetic patient, it follows that all these markers can be considered as poor prognostic markers in acute ischemic stroke.

\section{Bibliography}

1. Megherbi, S. E., Milan, C., Minier, D., Couvreur, G., Osseby, G. V., Tilling, K., ... \& Giroud, M. (2003). Association between diabetes and stroke subtype on survival and functional outcome 3 months after stroke: data from the European BIOMED Stroke Project. Stroke, 34 (3), 688-694. 2. Suslina, Z. A., Piradov, M. A., \& Domashenko, M. A. (2014). Stroke: the review of the problem (15 years later). Zhurnal Neurologists and Psychiatric Hymns SS Korsakova, 114 (11), 5-13.

3. Lieber, B. A., Taylor, B., Appelboom, G., Prasad, K., Bruce, S., Yang, A., ... \& Connolly Jr, E. S. (2015). Meta-analysis of telemonitoring to improve $\mathrm{HbAlc}$ levels: promise for stroke survivors. Journal of Clinical Neuroscience, 22 (5), 807-811. 4. Gentile, N. T., Seftchick, M. W., Huynh, T., Kruus, L. K., \& Gaughan, J. (2006). Decreased mortality by normalizing blood glucose after acute ischemic stroke. Academic emergency medicine, 13 (2), 174-180.

5. Williams, L. S., Rotich, J., Qi, R., Fineberg, N., Spain, A., Bruno, A., ... \& Tierney, W. R. (2002). Effects of admission hyperglycemia on mortality and costs in acute ischemic stroke. Neurology, 59 (1), 67-71.

6. Kohler, H. P. (2002). Insulin resistance syndrome: interaction with coagulation and fibrinolysis. Swiss medical weekly, 132 (19-20), 241-252.

7. Marques-Vidal, P., Mazoyer, E., Bongard, V., Gourdy, P., Ruidavets, J. B., Drouet, L., \& Ferrières, J. (2002). Prevalence of insulin resistance syndrome in southwestern France and its relationship with inflammatory and hemostatic markers. Diabetes Care, 25 (8), 1371-1377.

8. Arcaro, G., Cretti, A., Balzano, S., Lechi, A., Muggeo, M., Bonora, E., \& Bonadonna, R. C. (2002). Insulin causes endothelial dysfunction in humans: sites and mechanisms. Circulation, 105 (5), 576-582.

9. Imperatore, G., Riccardi, G., lovine, C., Rivellese, A. A., \& Vaccaro, O. (1998). Plasma fibrinogen: a new factor of the metabolic syndrome: a population-based study. Diabetes Care, 21 (4), 649-654.

10. Haapaniemi, E., Soinne, L., Syrjälä, M., Kaste, M., \& Tatlisumak, T. (2004). Serial changes in fibrinolysis and coagulation activation markers in acute and convalescent phase of ischemic stroke. Acta neurologica scandinavica, 110 (4), 242-247.

11. Berge, E., Friis, P., \& Sandset, P. M. (2001). Hemostatic activation in acute ischemic stroke. Thrombosis research, 101 (2), 13-21.

12. Reeves, M. J., Vaidya, R. S., Fonarow, G. C., Liang, L., Smith, E. E., Matulonis, R., ... \& Schwamm, L. H. (2010). Quality of care and outcomes in patients with diabetes hospitalized with ischemic stroke: findings from Get With the Guidelines - Stroke. Stroke, 41 (5), e409-e417.

13. Megherbi, S. E., Milan, C., Minier, D., Couvreur, G., Osseby, G. V., Tilling, K., ... \& Giroud, M. (2003). Association between diabetes and stroke subtype on survival and functional outcome 3 months after stroke: data from the European BIOMED Stroke Project. Stroke, 34 (3), 688-694. 14. Kiers, L., Davis, S. M., Larkins, R., Hopper, J., Tress, B., Rossiter, S. C., ... \& Ratnaike, S. (1992). Stroke topography and outcome in relation to hyperglycaemia and diabetes. Journal of Neurology, Neurosurgery \& Psychiatry, 55 (4), 263-270.

15. Anwar, M. M. U., Jahan, S. M. S., Afrin, S., \& Hossain, M. Z. (2017). Diabetic and Non-diabetic Subjects with Ischemic Stroke: Risk Factors, Stroke Topography and Hospital Outcome. Journal of Medicine, 18 (2), 75-79.

16. Jørgensen, H., Nakayama, H., Raaschou, H. O., \& Olsen, T. S. (1994). Stroke in patients with diabetes. The Copenhagen Stroke Study. Stroke, 25 (10), 1977-1984.

17. Wu, S., Wang, C., Jia, Q., Liu, G., Hoff, K., Wang, X., ... \& Liu, L. (2014). HbAlc is associated with increased all-cause mortality in the first year after acute ischemic stroke. Neurological research, 36 (5), 444-452.

18. Wu, S., Shi, Y., Wang, C., Jia, Q., Zhang, N., Zhao, X., ... $\&$ Investigators for the Survey on Abnormal Glucose Regulation in Patients With Acute Stroke Across China (ACROSS-China. (2013). Glycated hemoglobin independently predicts stroke recurrence within one year after acute first-ever non-cardioembolic strokes onset in a Chinese cohort study. PLoS One, 8 (11), e80690.

19. Jing, J., Pan, Y., Zhao, X., Zheng, H., Jia, Q., Mi, D., ... \& $\mathrm{He}, Y$. (2017). Insulin resistance and prognosis of nondiabetic patients with ischemic stroke: the ACROSSChina study (abnormal glucose regulation in patients with acute stroke across China). Stroke, 48 (4), 887-893.

20. Roquer, J., Giralt-Steinhauer, E., Cerdà, G., RodríguezCampello, A., Cuadrado-Godia, E., Jiménez-Conde, J., ... \& Ois, A. (2015). Glycated hemoglobin value combined with initial glucose levels for evaluating mortality risk in patients with ischemic stroke. Cerebrovascular diseases, 40 (5-6), 244-250. 